\section{Journals could share peer-review data}

Before dispensing with peer review in favour of open science, responsible scientists need to do everything they can to improve this centuries-old system. Our experience shows that journals that share information on all aspects of the peer-review process can foster transparency and accountability in publishing, while protecting the interests of authors, reviewers, editors and researchers.

As part of PEERE, a large

European Cooperation in

Science and Technology (COST)

Action project funded by the

European Union, researchers teamed up with the publishers Elsevier, Springer Nature (which publishes Nature) and Wiley to devise a protocol for sharing such information (see go.nature.com/2rx5ert). Our publicly available protocol has already been piloted in hundreds of journals and is tackling issues such as anonymity, privacy and data management.

This systematic investigation of the review process will enable more journals to recognize biases against the publication of innovative research, to test different peer-review models and to work out how best to engage and reward reviewers.

We invite scholars, editors and publishers to participate in the PEERE initiative by contacting us. Flaminio Squazzoni University of Brescia, Italy.

Francisco Grimaldo University of Valencia, Spain.

Ana Marušić University of Split, Croatia.

flaminio.squazzoni@unibs.it

\section{NIH competition to create 'eye in a dish'}

The National Eye Institute of the US National Institutes of Health (NIH) has launched a competition to develop a working model of the human retina from stem cells - namely, the 3-D Retina Organoid Challenge (see www.nei.nih.gov/3droc). This will help to clarify the mechanisms of retinal disease, stimulate new technologies and develop more effective therapies (see also G. Quadrato et al. Nature 545, 48-53; 2017).

There are other promising examples of NIH-funded 3D human-tissue models. Tissue chips are being derived from induced pluripotent stem cells in the Microphysiological Systems Program at the National Center for Advancing Translational Sciences in Bethesda, Maryland. And 3D biomimetic systems are being developed in the National Cancer Institute's Cancer Tissue Engineering Collaborative Research Program.

The 3D Retina Organoid Challenge will run alongside the National Eye Institute's Audacious Goals Initiative, which aims to restore vision by regenerating retinal neurons and their connections to the brain (www.nei.nih.gov/audacious). Paul A. Sieving National Eye Institute, Bethesda, Maryland, USA.

paulsieving@nei.nih.gov

\section{Pay countries to stop whaling}

We raise the possibility that countries opposed to whaling could stop other nations that continue the practice simply by paying them compensation. This idea is inspired by a survey we conducted in February 2016 in Australia and Japan.

We found that the maximum amount Australians would be willing to pay to discourage Japan's whaling programme was Aus $\$ 31.4$ (US\$23.6) per year per household. This exceeded the minimum compensation required by the Japanese for giving up their current whaling activities (see M. Wakamatsu et al. Mar. Policy 81, 312-321; 2017).

The benefits would go beyond those of a monetary transaction. Non-whaling countries would gain assurance of cetacean welfare and conservation worldwide. Whaling countries would no longer be ostracized by the international community.

Global evaluation of whaling involving all stakeholders would refine this bargaining. Important non-economic factors such as cultural values would need to be taken into account. These could be offset by, for instance, public education programmes in the ecological and conservation advantages of giving up whaling, and by developing alternatives to whale products that are acceptable to consumers.

Shunsuke Managi, Mihoko

Wakamatsu Kyushu University, Fukuoka, Japan.

managi@doc.kyushu-u.ac.jp

\section{Sustainability and resilience differ}

Sustainable urban development moved forward last year, when the United Nations adopted both the Sustainable Development Goal 11 on cities and the New Urban Agenda (see go.nature. com/2qz8ows). Unfortunately, these international policy documents interchangeably use two quite different concepts sustainability and resilience. We are concerned that policymakers confuse the two because academics do, which hampers implementation.

Resilience is a property of a complex system. For example, the Internet is resilient because it continues to function even when major nodes collapse. Resilience may not always be desirable witness dictatorships that are resilient across generations. It may also run counter to sustainability goals: for instance, efficiency reduces diversity and redundancy, both of which are key features of resilience.

This conflict is illustrated by high-density urban areas, which can be more efficient to run in terms of, say, energy distribution, communications and waste collection. However, these areas can also be vulnerable to extreme events such as flooding because they are less diverse (with few green areas, for example) and have few redundancies (in the form of back-up facilities and disaster-management processes).

The research community needs to be clear about the differences and synergies between sustainability and resilience. Only with clarity can such concepts be applied in policy and practice. Thomas Elmqvist ${ }^{\star}$ Stockholm Resilience Centre, Stockholm University, Sweden. thomas.elmqvist@su.se ${ }^{*}$ On behalf of 4 correspondents (see go.nature.com/2r23okn for full list).

\section{Senior scientists as allies for equity}

Asking the scientific system to fix itself from the bottom up could place an unacceptable burden on junior scientists (see J. Tregoning Nature 545, 7; 2017). Moreover, their efforts are likely to make little difference without the participation of senior colleagues.

Young researchers, especially women and those from ethnic minorities, are already forced to challenge the existing culture if they are to advance professionally. They face overt and unconscious bias, barriers to recruitment and unequal pay. They receive fewer grants and citations and must work harder for recognition than those with similar qualifications (see Nature 495, 22-24; 2013).

Such inequity could be corrected with the support of peers, as Tregoning proposes. But without higher-ranking allies, the efforts of young scientists face obstacles. To bring about change, senior scientists should couple their insight, experience and enthusiasm to that of younger colleagues. This would highlight problem areas, implement policy solutions and lead to cultural reform.

Christina Simkanin, Alison

Cawood Smithsonian Environmental Research Center, Edgewater, Maryland, USA.

simkaninc@si.edu 